\author{
Military Technical College \\ Kobry El-Kobbah, \\ Cairo, Egypt.
}

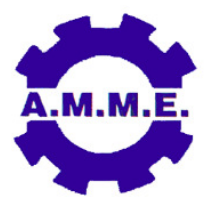

$17^{\text {th }}$ International Conference on Applied Mechanics and Mechanical Engineering.

\title{
PERFORMANCE ANALYSIS OF A SINGLE SHAFT GAS TURBINE USING BIOFUELS IN AN OBJECT-ORIENTED ENVIRONMENT
}

\author{
P. Christopoulou* and M. I. Hassan**
}

\begin{abstract}
Majority of the current energy sources in the world are based on fossil fuels, which will be someday depleted. In addition, fossil fuel greenhouse emissions are exponentially increased with the increased energy demand. The current research interest is to determine the sustainable alternative fuels that could be used as an alternative source of energy for power generation and they would provide environmental benefits including a reduction of $\mathrm{CO}_{2}$. In this study, the effects of the implementation of alternative fuels on the operation of an industrial gas turbine are investigated using performance models. The models have been created in an object oriented simulation environment. It was observed that the implementation of different fuels did not affect considerably the engine cycle parameters (less than $0.2 \%$ ) apart from the fuel flow rate. Finally, considering the case of Abu Dhabi, the impacts of the atmospheric conditions on the performance of the gas turbine have been analyzed. For all the cases, the fuel consumption in Abu Dhabi was higher than in ambient standard conditions in order to produce the same amount of power.
\end{abstract}

\section{KEY WORDS}

Power generation, gas turbines, alternative fuels, performance simulation, off - design operation

* Graduate student, Dept. of Mechanical and Materials Engineering, Masdar Institute of Science and Technology, Abu Dhabi, UAE.

** Assistant Professor (corresponding author: miali@masdar.ac.ae), Dept. of Mechanical and Materials Engineering, Masdar Institute of Science and Technology, Abu Dhabi, UAE. 


\section{NOMENCLATURE}

$\begin{array}{ll}\text { B25 } & \text { Blend 25\% jatropha algae in 75\% diesel } \\ \text { CME } & \text { Canola methyl ester } \\ \text { CO } & \text { Carbon monoxide } \\ \text { CO2 } & \text { Carbon dioxide } \\ \text { DME } & \text { Dimethyl ether } \\ \text { F-T } & \text { Fisher- Tropsh fuel gas } \\ \text { GHG } & \text { Greenhouse gases } \\ \text { HC } & \text { Hydrocarbon } \\ \text { LHV } & \text { Lower Heating Value } \\ \text { NO } & \text { Nitrogen monoxide } \\ \text { NOx } & \text { Nitrogen oxides } \\ \text { PROOSIS } & \text { PRopulsion Object Oriented SImulation Software } \\ \text { PSFC } & \text { Power Specific Fuel Consumption } \\ \text { RME } & \text { Rapeseed methyl ester } \\ \text { SME } & \text { Soybean methyl ester } \\ \text { WF } & \text { Fuel mass flow rate }\end{array}$

\section{INTRODUCTION}

The majority of energy sources worldwide is based on fossil fuels which have the largest carbon footprint. Electricity and heat generation currently accounts for around $42 \%$ of man-made $\mathrm{CO}_{2}$ emissions while transport accounted for nearly $23 \%$. The increased demand of electricity lead to a $50 \%$ increase of $\mathrm{CO}_{2}$ emissions from electricity generation between 2000 and 2013 [1]. In the past, industrialized countries were the primary greenhouse gases (GHGs) emitters but more recently, developing countries have taken the lead since their shares of GHGs emissions exceeded those of industrialized countries. At some point of their life cycle, all electricity generation technologies emit $\mathrm{CO}_{2}$. To reach a low-carbon world, a low carbon development path for developing countries is needed as well as the decarbonized of the energy sources of industrialized countries. Some of the imposed targets for the countries comply with the Kyoto Protocol are the reduction of GHGs from fossil fuel combustion and the reduction of direct industrial emissions. Renewable fuels (as called bio-fuels) are drawing considerable attention as an alternative source of energy to reduce the impacts of electricity generation on the environment and tackle climate change. The reduction of conventional fossil fuels resources worldwide is also a cause of concern.

Biofuels are liquid or gaseous fuels derived from biomass. Biodiesel is a potential environmental friendly alternative to petroleum diesel since its main characteristics are relatively similar to conventional diesel. It can be classified into two distinctive categories, first generation and second generation or advanced biodiesel, depending on the feedstock used for its production as well as the technology used to convert that feedstock into fuel. The former is normally produced by a variety of vegetables oils (e.g. rapeseed oil, soybean oil) and animal fats. Researchers, lately, are mainly interested on biodiesel derived from second or new generation biomass (e.g. algae, jatropha, and camelina) [2].. Biodiesel can be used pure or blended in any proportion with petroleum diesel and it can be used with no modifications in any gas turbine [3]. 
However studied showed that the blending proportion could be one of the parameters effecting the emissions [4]-[5].

Several studies have been conducted regarding the use of alternative fuels to fire Internal Combustion Engines ]-[10] however only a limited amount of experimental studies have been done in gas turbines in order to analyze the performance and emissions using biofuels. Recently, Habib et al. [11] made experimental tests using pure biofuels (soy methyl ester (SME), canola methyl ester (CME), recycled rapeseed methyl ester (RRME)) and their blends with Jet-A fuel in 30kW gas turbine engine. Giving as main results, that indeed the implementation of biofuels resulted to a decrease of $\mathrm{CO}$ and NO emitted pollutants compared to Jet-A with no significant reduction in static thrust. As presented in their study, Moliere et al experimentally investigated the use of bioethanol in a gas turbine Frame 6B and they concluded that the use of $100 \%$ pure bioethanol lead to a $50 \%$ reduction of NOx. In the year 2010 , Rehman et al. [12] proved from their experimental work that $\mathrm{CO}$ and $\mathrm{HC}$ emissions from a gas turbine fired with diesel - biodiesel blends are lower than that obtained with diesel. Tests [13] have also indicated that the use of dimethyl ether (DME) to a gas turbine for power generation leads to a cleaner combustion than the use of methane, which is the major component of natural gas. Numerical studies [14] have shown that the implementation of low heating value fuels can lead to an increased fuel consumption compared to natural gas as well as techniques such as air extraction at the compressor and adjustment of the inlet guide vane can achieve a safe operation of the engine.

The objective of this study is to contribute to the understanding of the performance of gas turbine engines fired by sustainable alternative fuels for power generation as part of the sustainable energy production policy. Considering the potential alternative fuels that can be used to replace diesel in an industrial gas turbine based on the literature review, seven alternative fuels have been selected for this study. A model for an industrial gas turbine have been created and the use of the considered alternative fuels has been studied. The model results (or predictions) have been compared to those obtained by using Diesel to the model. The approach followed to create the gas turbine model has been validated using experimental data from the literature review. By adapting a gas turbine model that can accurate simulate the performance of a gas turbine allows to perform numerical simulation for different fuels with no additional cost.

\section{SELECTION OF ALTERNATIVE FUELS}

The use of alternative fuels to fire gas turbines is commonly accepted that will help the task of reducing the environmental impacts of electricity generation. There are a number of different alternative fuels that could be implemented in industrial gas turbines. The first objective of this study is to make the proper selection of the biofuels that are going to be tested on the gas turbine model. The selection will be done according to availability, composition and physical properties of the fuel. Gökalp and Lebas [15] listed listed the gaseous and liquid fuels that can be used for that purpose as followed: i) vegetables oils, ii) esters, iii) flash pyrolysis oils, iv) ethanol, v) methanol, vi) synthetic fuels (biomass to liquids), vii) dimethyl ether, viii) biogas of gasification, ix) biogas of waste mechanization, $x$ ) biogas of slow pyrolysis and xi) industrial process gases rich in hydrogen. 
For the purpose of this study we selected seven different alternative fuels in order to be numerically simulated on the gas turbine model. The first five are the leading alternative candidates (soybean oil methyl ester (SME), canola oil methyl ester (CME), rapeseed oil methyl ester (RME) and jatropha algae) and a blend of $25 \%$ jatropha algae in 75\% diesel (B25). The remaining two are Dimethyl ether (DME) and Fisher-Tropsh (F-T) fuel gas. DME can be produced from diverse materials including biomass and F$T$ process can be utilized in order to produce liquid biofuels starting with the biomass syngas. The fuels produced by this process can be economic alternatives for electricity generation applications [5]. On Table 1, the properties of the alternative fuels considered in this study are presented as they were retrieved from [11], [12] and [16].

\section{MODEL DESCRIPTION}

The performance model of the industrial gas turbine has been created in the PROOSIS v3.6.14 simulation environment [17]. It is a flexible, stand-alone software that has been built taking advantage of the object oriented technique. It can perform steady-state and transient calculations as well as a wide range of different calculation types (e.g. single or multi-point design, off-design, test analysis, sensitivity, parametric etc.). It contains an advanced graphical user interface which allows modular model building by simply "drag and drop" the required component icons from the existing libraries. The libraries can be extended with new components or physical models. Each component icon contains the mathematical model of the corresponding real-world component which could be a single engine component, a complete engine, a control system etc. The components communicate through the ports which define the set of variables to be interchanged between them. For the work reported here, the TURBO library has been used to create a single shaft industrial gas turbine. TURBO library uses performance modeling techniques that have been accepted by the industry.

For this study, the three-dimensional tables that will be used in order to calculate the caloric properties of the certain alternative working fuels in the engine model have been generated with the NACA CEA software [18].

Before starting our analysis, the model of $30 \mathrm{~kW}$ gas turbine (Figure 1) has been built using the same components and its results have been compared with the experimental results for the same gas turbine [12]. The comparison of the experimental and numerical power specific fuel consumption is presented on Figure 2.The observed errors could be an effect of the errors in experimentation because of the instruments that have been used.

\section{Case Study}

The values of the main engine performance parameters at sea-level standard conditions for the performance model that has been created are presented on Table 2. Further information such as: combustion chamber pressure drop, compressor polytropic efficiency, turbine isentropic efficiency, mechanical efficiency and others were assumed in order to establish the design point of the performance model. Simulations were carried out for the model when diesel is used as fuel in order to establish the reference point against which the alternative fuels selected for this study will be compared. Appropriate maps have been used to describe the performance of 
the turbomachinery components and the burner efficiency is a function of burner loading. Shaft losses have been taken into consideration.

Considering the weather conditions in UAE and more specifically in Abu Dhabi, a performance analysis of the gas turbine has been executed. Real data for the ambient temperature, pressure and relative humidity have been retrieve from Abu Dhabi International Airport and the average temperature, pressure and relative humidity for each season have been used.

\section{Alternative Fuels Results}

For each of the aforementioned alternative fuels, simulations have been executed by specifying the power. The implementation of different fuels to the performance model did not affect considerably the engine cycle parameters (less than $0.2 \%$ ) apart from the fuel flow rate. On Figure 3, the impacts of operating the gas turbine with alternative fuels for standard ambient conditions on the fuel flow rate is presented in a bar chart graph. The effects of the ambient temperature, pressure and relative humidity on the fuel mass flow rate are demonstrated on Figure 4 compared with the standard ambient conditions.

From the reported work, we can conclude that the use of B25 has the smallest effect on the fuel consumption of the engine while when we replace the diesel with DME the fuel consumption is almost double. The implementation of jatropha algae to the industrial gas turbine engine leads to the minimum fuel mass flow rate compared with the other alternative fuels. The ambient conditions effect the fuel consumption rate significantly. More specifically, in summer when the temperature rises the fuel consumption in Abu Dhabi is $2.6 \%$ higher than in ambient standard conditions in order to produce the same amount of power. However, as it is presented in Figure 4, the implementation of DME has the lowest increase in the fuel consumption for all the seasons.

\section{SUMMARY AND CONCLUCIONS}

A performance model of an industrial gas turbine has been developed in an object oriented simulation environment to study the effects of the use of alternative fuels on its operation performance.

The model of an industrial gas turbine allows us to carry out simulations varying different parameters and testing the effects of those on its performance. Different calculation can be performed using the specific simulation environment (off-design, sensitivity, optimization etc.).

Firstly, the selection of the alternative fuels is presented. For this study, seven alternative fuels have been chosen to replace diesel in the engine's model. Simulations carried out for the model of a $30 \mathrm{~kW}$ gas turbine and the results have been validated using previously published experimental results. The model of an industrial gas turbine has been simulated initially for the case of diesel. The results obtained from the implementation of the alternative fuels have then been compared to those for the case of diesel. For the fuels considered in this study, there are no noteworthy impacts on 
the engine's performance apart from the fuel consumption that varies according to the fuel's lower heating value.

To this end, based on the results, we concluded that blended fuels appear to be the most appropriate alternative to diesel for the parameters considered in the presented study. More specifically, biodiesel blend of jatropha algae with diesel can be one of the alternative fuels for gas turbine applications. Other parameters should also be taken into consideration to allow a complete evaluation of their use (e.g. economics, availability, emissions etc.).

\section{REFERENCES}

[1] International Energy Agency, " $\mathrm{CO}_{2}$ emissions from fuel combustion", IEA Statistics, pp. 7-14 (2015).

[2] S.N. Naik, G.V. Vaibhav, R.K. Prasant, D.K. Ajay, "Production of first and second generation biofuels: A comprehensive review", Renewable and Sustainable Energy Reviews, Vol. 14, pp. 578-597 (2010).

[3] K.K. Gupta, A. Rehman, R.M. Sarviya, "Bio-fuels for the gas turbine: A review", Renewable and Sustainable Energy Reviews, Vol. 14, pp. 2946-2955 (2010).

[4] C.D. Bolzo, V.G. McDonell, "Emissions optimization of a biodiesel fired gas turbine", Combustion Institute, Vol 32, pp. 2949-2956 (2009).

[5] D. Sequera, A.K. Agrawal, S.K. Spear, D.T. Daly, "Combustion Performance of Liquid Biofuels in a Swirl-Stabilized Burner", Journal of Engineering for Gas Turbines and Power, Vol 130, (2008).

[6] M.M. Roy, W. Wang, M. Alawi, "Performance and emissions of a diesel engine fueled by biodiesel-diesel, biodiesel-diesel-additive and kerosene-biodiesel blends", Energy Conversion and Management, Vol.84, pp. 164-173 (2014).

[7] D.M. Korres, D. Karonis, L. Evripidis, M.B. Linck, A.K. Gupta, "Aviation fuel JP-5 and biodiesel on a diesel engine", Fuel, Vol 87, pp. 70-78 (2008).

[8] D.K. Bora, D.C. Baruah, L.M. Das, M.K.G. Babu, "Performance of diesel engine using biodiesel obtained from mixed feedstocks", Renewable and Sustainable Energy Reviews, Vol. 16, pp. 5479-5484 (2012).

[9] R. Mohsin, Z.A. Majid, A.H. Shihnan, N.S. Nasri, Z. Sharer, "Effect of biodiesel blends on engine performance and exhaust emission for diesel dual fuel engine", Energy Conversion and Management, Vol 88, pp. 821-828 (2014).

[10] I. Barabas, A. Todorut, D. Băldean, "Performance and emission characteristics of an $\mathrm{Cl}$ engine fueled with diesel-biodiesel-bioethanol blends", Fuel, Vol 89, pp. 3827-3832 (2010).

[11] Z. Habib, R. Parthasarathy, S. Gollahalli, "Performance and emission characteristics of biofuel in small-scale gas turbine engine", Applied Energy, Vol. 87, pp. 1701-1709 (2010).

[12] A. Rehman, D.R. Phalke, R. Pandey, "Alternative fuel for gas turbine: Esterified jatropha oil - diesel blend", Renewable Energy, Vol.36, pp. 26352640 (2011).

[13] M.C. Lee, S.B. Seo, J.H. Chung, Y.J. Joo, D.H. Ahn, "Combustion performance test of a new fuel DME to adopt to a gas turbine for power generation", Fuel, Vol. 87, pp. 2161-2167 (2008). 
[14] E.B. da Silva, M. Assato, R.C. de Lima, "Performance Predictions of Gas Turbine UUnder Different Strategies Using Low Heating Value Fuels", Proccedings of ASME Turbo Expo 2013, GT2013-96013 (2013).

[15] I. Gökalp, E. Leba, "Alternative fuels for industrial gas turbines (AFTUR)", Applied Thermal Engineering, Vol. 24, pp.1655-1663 (2004).

[16] T.A. Semelsberger, R.L. Borup, H.L. Greene, "Dimethyl ether (DME) as an alternative fuel", Journal of Power Sources, Vol. 156, pp. 497-511 (2006).

[17] A. Alexiou, T.Tsalavoutas, "Introduction to Gas Turbine Modelling with PROOSIS", EA International, First Edition, (2011).

[18] S. Gordon, B.J. McBride, "Computer Program for Calculation of Complex Chemical Equilibrium Composition and Applications", NASA RP1311, National Aeronautics and Space Administration, Washington, D.C., (1994). 
Table 3. Properties of selected fuels.

\begin{tabular}{|c|c|c|c|c|}
\hline Fuel & Density $\left(\mathrm{kg} / \mathrm{m}^{3}\right)$ & & $\begin{array}{c}\text { Lower Heating } \\
\text { Value } \\
(\mathrm{MJ} / \mathrm{kg})\end{array}$ & \\
\hline Diesel & 847.0 & (Ref) & 42.60 & (Ref) \\
\hline DME & 662.0 & $(-21.84 \%)$ & 28.80 & $(-32.39 \%)$ \\
\hline Jatropha algae & 748.0 & $(-11.69 \%)$ & 44.20 & $(+3.76 \%)$ \\
\hline Blend 25\% (B25) & 869.0 & $(+2.60)$ & 42.89 & $(+0.68 \%)$ \\
\hline $\mathrm{F}-\mathrm{T}$ & 801.0 & $(-5.43 \%)$ & 43.94 & $(+3.15 \%)$ \\
\hline SME & 880.0 & $(+3.90 \%)$ & 38.00 & $(-10.80 \%)$ \\
\hline RME & 882.0 & $(+4.13 \%)$ & 37.30 & $(-12.44 \%)$ \\
\hline CME & 883.0 & $(+4.25 \%)$ & 37.40 & $(-12.21 \%)$ \\
\hline
\end{tabular}

Table 4. Engine Parameters.

\begin{tabular}{lcc}
\hline \hline Parameter & Value & Units \\
& & $\mathrm{kW}$ \\
\hline Delivered Power & 5670 & $\mathrm{~kg} / \mathrm{s}$ \\
Inlet air mass flow rate & 27.80 & $\mathrm{rpm}$ \\
Turbine Speed & 11085 & $\mathrm{~kg} / \mathrm{kWh}$ \\
Specific fuel consumption & 0.292 & - \\
Overall pressure ratio & 11.92 & $\mathrm{~K}$ \\
Turbine Inlet temperature & 1236 & \\
\hline \hline
\end{tabular}




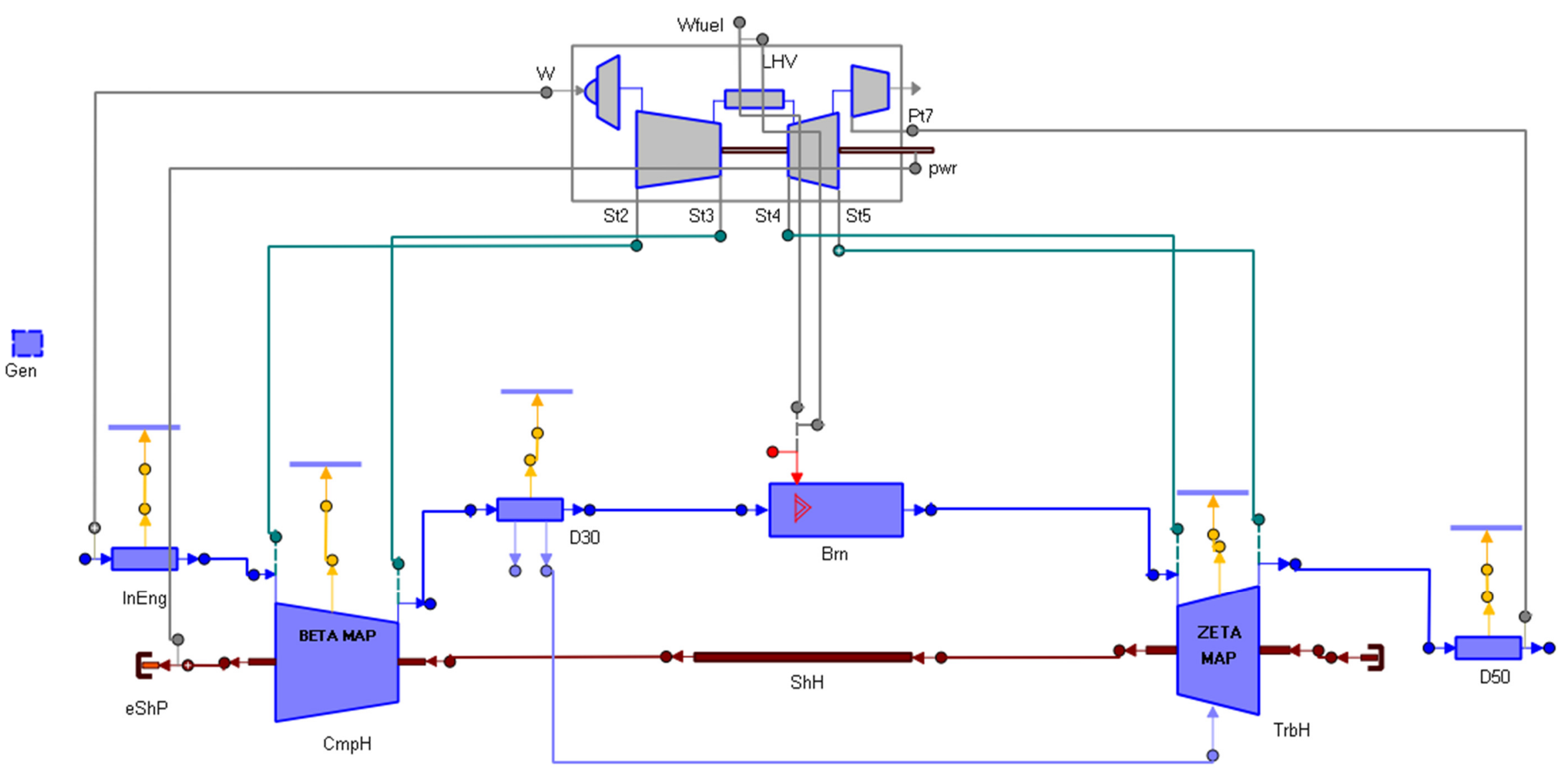

Figure 1: Performance model. 


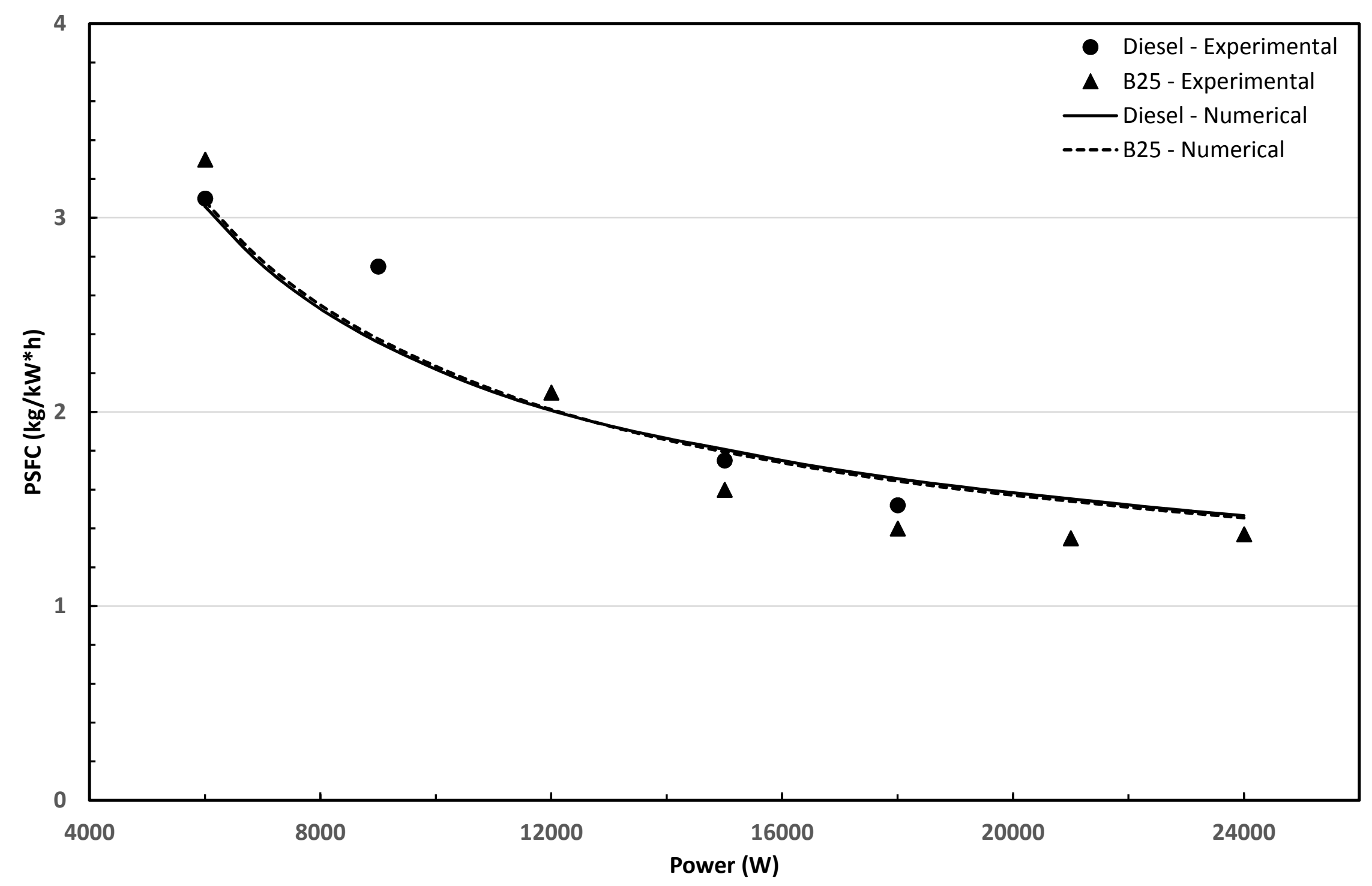

Figure 2: Numerical and experimental power specific fuel consumption. 


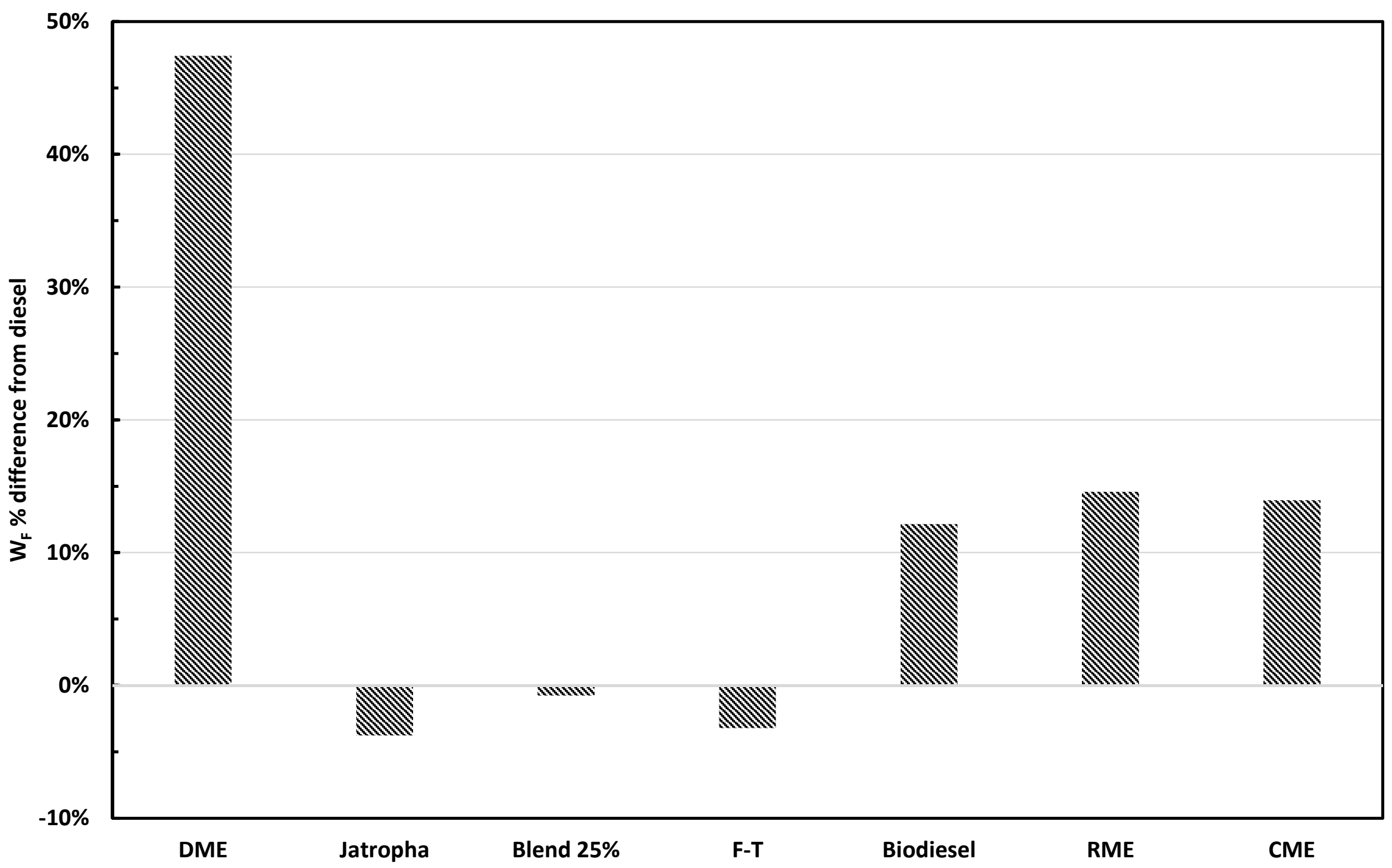

Figure 3: Impact of alternative fuels on engine fuel consumption. 


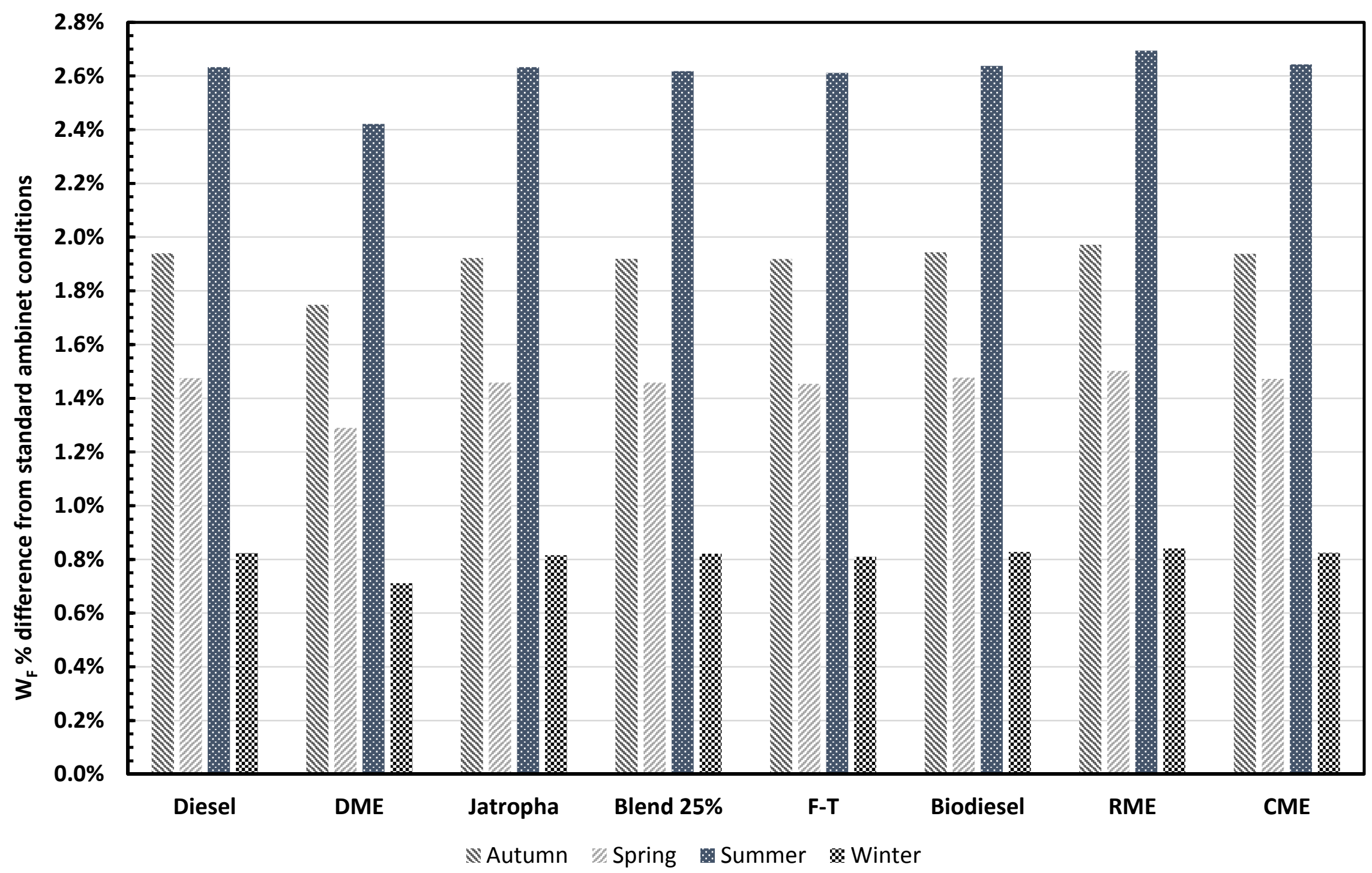

Figure 4: Effect of ambient conditions on engine fuel consumption 